\title{
Phenomenology and Appropriation
}

\section{Thomas Langan}

University of Toronto

I intend to defend a proposition unpalatable to Husserlians of the Strict Observance, to wit that phenomenology, properly understood, leads inevitably to an appropriative undertaking. By appropriation I mean the reflective-interpretative process of taking a stand towards, and thus accepting responsibility for, one's situation and one's being. Appropriation is a certain coming to grips with history which a properly understood phenomenological method will serve.

To defend this proposition, the following assertions are put forward and require defense:

1. All description is reflective.

2. All reflection is interpretative; all reflection is an act of Verstehen.

3. All interpretation is historically founded and conditioned (all interpretation is geschichtlich, in Heidegger's sense of that term).

4. Therefore all phenomenology is interpretative-historical, and hence must be appropriative.

5. Appropriation demands a critical coming to grips with the implicit (and sometimes explicit) claims of that which presents itself. Mature, adequate appropriation requires the search for the logos of that which appears-it is therefore phenomenological.

6. The critical confrontation required by the appropriative act leads naturally to, and is confirmed by, a praxis. Phenomenology, which is often thought of as purely descriptive, is therefore, if all of the above propositions are true, in the service of action.

1. All description is reflective. Properly understood, this proposition is self-evident. Description requires a certain deliberate distancing of the subject from the spontaneous flow of lived experience (the erleben becomes an Erlebnis when an aspect of the total lived experience is attended to, singled out for consideration and bent back upon by the describing subject). One does not just describe. One decides to describe. A situated motivation is required. There is some reason for setting out to describe that which is described, and for attending to it in the particular way which characterizes the given act of description. It is in this sense, then, that- 
2. all reflection is interpretative, and hence never "presuppositionless." This insight, if true, strikes a death blow at the Husserlian project of the epoché, if this is thought to achieve a suspension of presupposition. I shall not here flog a dead horse; the more naive forms of understanding epoche are defended today by no one, and Husserl himself, by the time of Krisis der europaischen Wissenschaften was himself far from a naive position. ${ }^{1}$ Nevertheless, the proper understanding of the proposition that all reflection is interpretative is the key to the present paper. Without pretending to be able here to reproduce in condensed form the analysis presented by Heidegger in the famous sections 31 and 32 of Sein und Zeit ("Das Da-sein als verstehen," and "Verstehen und Auslegung,"), I would simply draw the reader's attention to one central fact. When I have decided for some reason, arising in some definite situation which itself contributes to setting a context, to describe something in a particular way, then, however intensely, however "objectively" present the experience of the thing to be described, the describing itself is interpretative. By interpretative I mean that the describing subject accepts from the possibilities at hand in his experience certain givens which are "taken up" while the remainder are left on the horizon, perhaps as hidden ground. The selected possibilities become the attended-to experience; they are viewed in a certain way, which way is determined, not only by the inherent ontic structure of the possibility itself, but by the subject's particular capacity of seeing. One subject will be able to see in a thing aspects for which another subject is not prepared. A subject who sees something that is not genuinely based in the ontic possibility-structure of the experienced thing is, of course, fantasizing, whether he is simply aware of it, as we sometimes are, or not. In all events, the subject must bring to the experience a certain definite capacity for experiencing and, if he is describing, a capacity for description. To describe is to take up those possibilities, coming from the contribution of the thing and from the contribution of the experiencer and describer, and to open for them a new future by laying out the description (the literal sense of Auslegung is here an excellent way of putting what the describer does), as he unfolds, profile by profile, the experienced object. In the process of "laying out" the description, the subject participates in the creation of new possibility, for the description goes beyond the mere experiencing as the experiencing goes beyond the mere being-an-ontic-possibility which itself is only revealed through the experiencing. The description, after all, is something that can be built upon; it is a kind of taking possession, an appropriation of the experience, and through the experience, of the thing. The resulting cognition of the thing is my work; I now have a vested interest in it; I am prepared to defend it.

3. But what is it precisely in all this that has a history? Is it the experiencing-describing, or is it the thing described? Actually it is 
both; each has a history, in a different way, and in the act of cognition these histories encounter one another and articulate with one another. I describe a tree. My act has a history; the phenomenologist manifests a peculiar kind of interest in the tree particular only to philosophy professors. The poet sings the tree, his celebration makes it vibrate for the happy listener. The philosopher talks more about describing the tree than he ever actually describes it, but when he finally does, the poor tree becomes the lumpen-proletariat of the poetic world! Be that as it may, this particular McIntosh Apple in my garden, on the eve of its annual Springtime Spectacular, has its own history, independently of anything I may do to take notice of it. Inscribed in its present ontic being, founding the possibilities of its being further known, are many traces of its having-been, some aspects of which I single out, for my own reasons, from my own not always fully aware motives, in recounting elements of its history. In the process of describing aspects of its history, those aspects are taken up into my discourse, they have moved into the realm of my conscious possession, and in being expressed, they become a new fund of possibility. From these few reflections it should now be clear what is meant by the third proposition: "All interpretation is historically founded and conditioned." But does it follow from the geschichtlich character of interpretation, that-

4. all phenomenology is interpretative-historical and hence must be appropriative? If this proposition is taken as excluding the possibility of straightforward description of objects-experienced without the need for a critical moment of evaluation as condition for fully mature appropriation, then obviously it would be false. The lower degrees of appropriation, those taking-possessions which are unaccompanied by critical reflection, are always possible, and indeed the press of daily life seems to require us to limit our "coming to grips" with things often to a level of very superficial and minimally responsible encounter. But of its nature, all experience calls for, and is essentially incomplete without, the critical coming-to-grips which alone supplies the ultimate context without which its full meaning remains hidden: that the context is the hidden ground provided by the totality of our experience operating spontaneously and uncritically in the form of a kind of "natural faith" which gives the tone to our judgments even though we may be only dimly aware of it. Phenomenology, in its maturity as a full-blown philosophical method, must be critical, that is, it should invite the describer to increase his awareness of the context and ground of his description and to question its adequacy as a response to the questions put to us by the situation in which we find ourselves. Criticism should not be limited to deciding merely whether a given description is an accurate expression of the thing one intends to describe. The critic should place in question the accepted canons of accuracy: he should 
question the adequacy of the description as an answer to the implied question; and finally he should question the adequacy of the question as an expression of the needs inherent in the situation into which he has been "thrown." A description is adequate only if it responds accurately (that is the ontic aspect) and adequately (that is the ontologic aspect) to the question asked. But whether the question implied by a description is itself the result of an adequate grasp of the needs of the situation is a central issue of responsibility, the heart of the appropriative enterprise.

5. Appropriation demands a critical coming to grips with the implicit (and sometimes explicit) claims of that which presents itself. What "presents itself," in most general terms, is the spontaneously lived situation, interpreted in the light of one's on-going implicit judgment of how it stands with the world, one's "natural faith." Phenomenology is rooted in need, because what appears (phanasthai) in the situation are challenges to the individual, needs both interior to the individual himself, and exterior-the needs of the other person, of the institutions within which we work and by which we are formed, and the needs of things. The ability to respond to these needs depends, objectively, on adequate appreciation of them, and, subjectively, on an overcoming of characterological and psychopathological barriers to our facing them.

The tree does not need phenomenological description. The need to describe the tree may arise in the context of a certain philosophical questioning in the course of which I cast about for an example of something natural, imposing, and relatively stable. I may need to appreciate the tree in many respects, to satisfy many aspects of my human nature, but it would be merely romantic to suggest that the tree itself needs appreciating. It does need care, however, if it is going to bear fruit. The fruit is of course my need. Without pruning, spraying, fertilizing, the yield will be meagre or non-existent. If the situation, as I interpret it, calls for fruit and not mere decoration, then I shall have to respond, if I am able, accordingly. Responsible action answering to such a short-range, highly focused project as getting a tree to bear fruit, requires a very limited appropriation of the pertinent techniques. Such a project arises, as a need, out of a context of natural appetites, economic possibilities (markets, prices, etc.), traditionally formed gastronomic tastes, and an understanding of local agricultural possibilities.

Now, the relative autonomy of such sub-systems of human need is such that they neither demand nor especially invite deeper inquiry into hidden grounds (the Logos!) of the sort which make a LeviStrauss famous when he manages to bring them to view (as for example in Le cru et le cuit). Nor should the philosopher suggest that there is somehow something shameful in being satisfied with an adequate answer to a practical question that is reasonably clear in itself. 
But there exists in man a need to uncover deeper questions, implying broader contexts, having to do more with the destiny of mankind as such and ultimately with the happening of Being itself. This need is rooted, according to Aristotle, in the nature of intelligence itself, which by its form is meant to know all Being. Now, this aspect of our nature does not render illegitimate the limited pursuit of practical ends dictated by another fundamental aspect of our nature--our incarnation. Abuse in this regard arises only when the pursuit of such local aims becomes an all-absorbing block to the pursuit of ultimate truth, which itself is a genuine ontic (and not just ontologic) needit is something, I would claim, which appears spontaneously in the field of our experience: By virtue of his need to direct his action in a way that takes into account the relevant forces at work in his situation, and his need to direct his life in a way that makes some kind of defendable sense, ${ }^{3}$ the human existent inevitably forms some set of directive principles, based on his on-going assessment of how it stands with the world - what I have termed a "natural faith." These ruling projects give structure and direction to his life, a schema directeur that is often not without elements in tension, due to a degree of inconsistency in the pursuit of goals.

6. Phenomenology, understood as part of the appropriative enterprise, ought to become central to the pursuit of sense in life, as the individual becomes aware of the need to introduce method into the critical examination of the principles directing his action. In the course of acting, questions arise. Upon the scope and seriousness of our action depends to considerable measure the questions which get imposed upon us. Phenomenology, guided by the questions arising from praxis, in turn aids praxis by providing a method to discern and probe the structure of the most adequate context, within which the understanding of a strategy - a course of action-should arise. The effort to carry out the strategy in turn throws light on the adequacy and accuracy of our reading of the context, as well as turning up new experience which requires further questioning. As our understanding of the ultimate context evolves, our expression of it in the form of guiding principles evolves as well. The effort to examine those principles critically in the light of what we have been able to see of the ultimate context provides whatever grounding of our "natural faith" we can hope for. Under the best circumstances, an important element of natural faith proves irreducible: there is no possibility of so "laying out" the ultimate perception of the ground of one's action as to compel consent by any fair-minded hearer of the description. The probing of the structures revealed in the examination of the ultimate contexts is never complete, is never really satisfying. Moreover, new experience is forever confronting us. That is why the pursuit of phenomenology as appropriation breeds humility, not arrogance. 
But now that we have discussed the historical (more exactly, the geschichtlich) nature of the phenomenological task, some might wonder about the appropriateness of calling a method of historical appropriation "phenomenological." As appropriation seems aimed at illumining the nature of the forces at work forming the individual existent and the situation in which he must operate, rather than at uncovery of a transcendental structure of consciousness-the aim of Husserl's quest-might it not be misleading and confusing to think of appropriation as phenomenological?

On the contrary, I have intended to show, not only that phenomenology, properly understood, inevitably leads to appropriation, but also that mature, adequate appropriation is phenomenological. The entire argument, to this point, supports the first contention. As to the second, that appropriation, properly conducted, will be phenomenological, consider further this: What is to be appropriated is that which appears (phanasthai). This is investigated, as called for by the phenomenological method, without discrimination as to its "subjective" and its "objective" components. What the appropriator seeks, in attempting to illumine as fully as possible that which appears and then to come to grips critically, personally with it, is its ground (logos), which he pursues first in the form of a search for the ultimate context, pursued both synchronically and diachronically. If the logos of what appears is considered, as I do here, to be the ultimate context, understood as an all-englobing structure, then we must consider certain problems which arise, first in the pursuit of the adequate synchronic context, then we shall consider what is involved in the pursuit of the adequate diachronic context.

In pursuing the widest possible synchronic context, the appropriator seeks to situate the experience upon which he is reflecting in relation to the entire field of relevant forces he is able to see operating in the present situation. The question is always what is "relevant." To understand the problem we must consider some elementary facts about structures. By a "structure" I mean any sort of a whole, the belonging together of whose parts is in some way perceived and the sense of which belonging together of the parts can potentially be comprehended. If one fails to perceive the various parts as belonging in some way in some sort of whole, the various parts are then simply experienced as self-standing individuals. But the moment things are perceived as belonging together in some sort of whole, then the perceived structure has to manifest some degree of closure, it must enjoy some sense in itself. It is because structures appear in our experience and can be grasped as such that short-range practical projects can even occur to us and be pursued. But it is also the reason why the mind can find a certain repose in its comprehension of figures, why it can fail to press on to the larger questions any figure always $\mathrm{im}$ plies. Yet every figure of its nature always transcends itself, if we 
will only recognize it. Here it should suffice to call attention to the several ways in which every figure points beyond itself:

1. As a type: The mind is able to abstract a general configuration from every concrete figure in virtue of the formal intelligibility intuited when the mind grasps the peculiar kind of belongingness of the parts. Even though existentially there may be only one such "widget" in existence, this type of "widgetness" is understood as a general formal possibility. Through the mediation of the abstracted concept, this concrete widget is attached to all potential widgets whatever.

2. As a moment in a more general context, that is itself part of a larger structure. This is true both formally and existentially. Formally the type is itself specific to a higher formal genus. It may also be simply part of a larger, more complex structure. This oak is both a member of a species, which itself comes under a genus, and also an element in a garden. Existentially, this thing is sustained by conditions and causes which, while not entering immediately into its formal intelligibility, are nevertheless potentially part of its "explanation."

3. As a manifestation (a "showing forth") of something, the figure is usually not known for itself qua this intelligible structure but as a presentation of a reality that is much grander than this, or any particular grasp we may have of it. When language and Hermeneutics philosophers speak (often rather timidly) about the referential sense of the word, it is this fundamental aspect of the structure's transcendence to which they make their deferential nod. If the phenomenologist remains in living contact with experience as it is actually suffered and actively pursued, he cannot fail to see that in real life knowledge is knowledge of dynamic processes of forces captured tentatively in meeting points of relations, which we call things, which, while manifesting the tendency to closure we spoke of a moment ago, are tissues of connections leading out in all directions endlessly. The search for the Logos is endless. It leads on not just synchronically, but also leads back, diachronically, along the line of the historical, having become part of all the elements of the many structures we now perceive.

Which brings us to the second kind of appropriative reaching-out for the largest context-the diachronic appropriation. The lines of force which criss-cross in the present synchronic setting themselves reveal a certain depth in time-they are lines which not only come from without a present figure from other simultaneously present structures but from back in time, either as transmissions of continual natural history or as transmissions, through institutions, of cultural history. The question is, to what extent this depth in time makes up part of the essential intelligibility of the present structure. 
To what extent should the history of the elements which are woven into the present structure enter into its essential intelligibility? As we have suggested, because a structure has a sense in itself, it can, to some degree, be comprehended by considering the inherent intelligibility of its parts' belonging together. But the moment we seek ultimate context because we are seeking the largest possible understanding, then every opening out, synchronic as well as diachronic, becomes relevant.

But there is a special relevance to the diachronic, historic dimension which becomes clear when action is considered. The agent, seeking to understand what he can and what he should do, is confronted with the task, not only of situating the forces presently operating in the actual situation in correct relation to one another, but, when anticipating how those forces may unfold, he has to understand what he can of their own inherent dynamics, as condition for determining how the forces in tension can balance off or deflect one another. To understand their inherent dynamics he must learn how they have become what they are, tracing back their lines of development. Many of the natural forces at work in man's arena evolve so slowly in relation to the time frame of human action that they can be treated for all practical purposes as though stable. But not all, as the environmental movement testifies. The human forces, on the other hand, except to the extent they are stamped by human nature, manifest utmost change. In seeking to discern the sense of direction of basic developments in order to extrapolate these lines of force, one is aware of the highly tentative nature of the enterprise. The great number of variables, the unpredictability of "feedback" phenomena of reflection, indeed, the difficulty of anticipating changing rates in the growth of awareness (the phenomenon made central by Hegel); all the things we lump together rather unclearly under the label "freedom," render the extrapolation hazardous. And yet somehow it helps to search far back along the lines of development.

A few years ago at Buckminster Fuller's 80th birthday party someone asked him rather ingenuously how he had been able to anticipate so many developments so far in advance. "If you want an arrow to shoot far," he replied, "you must pull the bow far back!" By definition one cannot foresee the most daring creative leaps forward, but one can learn to discern everything that is more regular, more inertial, and especially that which is foundationally natural (and therefore persistent) in human affairs through reconstruction of the long course of great traditions unfolding with a certain intelligibility.

But, to resharpen our question, how is such appropriation of the sense revealed by the diachronic line of development phenomenological? Again, what one is appropriating is that which appears. The appropriator is concerned with the history of that which, in the pres- 
ent experience of the situation, and of myself in the situation, presents itself as engaging our attention. This field of experience is neither subjective nor objective, nor is its history. This being beyond the subject-object distinction is a hallmark of the phenomenological attitude. The interpretation of canonical texts in the effort to get as close as possible to the founding vision of an explicit tradition is an enterprise concerned both with the "objective" state of the extant text and with the "subjective" intention of the author. The study of the dynamics of an institution involves both the objective descriptions of offices and the subjective appreciation of the psychological aspects of group dynamics.

Again, the goal of the appropriator is phenomenological: he is seeking to lay bare the structure of the tradition. Is it legitimate to speak of the essence or structure of a tradition as its eidos or logos? Since Plato and Aristotle first reflected critically on the nature of knowing, philosophers have agreed that insight seeks to discern in the midst of the totality of what is experienced the essence which alone can reveal the meaningful place of each of the particular moments of "experience" or "data," (depending on whether one is emphasizing the noetic or the noematic pole of the experience). The search for the enduring as opposed to the ephemeral; for that which unites many acts into a sustained movement, as opposed to that which tends to tear up the tradition; for the goal of the underlying fundamental project, in contrast to necessary temporizing and compromising with the pressures of the momentary situation; this is what science is about. Such science is phenomenological when it excludes nothing from the field of experience, either because it is "subjective" or because it is "objective." The distinction, essentialaccidental, runs across the distinction, "subjective-objective."

But is appropriation, with its emphasis on a critical coming to grips with the essence of the traditions and the situation within which they meet, perhaps something more than phenomenological? Does the fact that appropriation stands in the service of authenticity, that is the self's assumption of full responsibility for itself through its ability to respond to the deepest needs and possibilities of the situation, ${ }^{4}$ mean, with its call for action, that it is ek-sistential in some sense that goes beyond classical phenomenology's understanding of its method?

The contention, in this paper, has been that phenomenology profoundly enough understood in its implications leads necessarily to appropriation, and that appropriation depends on adequate phenomenological reconstruction of the situation and the traditions operative within it as a necessary condition for its adequate pursuit. The notion of how truth is to be pursued running through this essay-the notion that nothing in experience is to be excluded but 
rather that all that which manages to show itself by attracting our attention should be methodically explored by seeking to view it always in the largest possible context, and that within these contexts, synchronic and diachronic, the knower should seek the essential structures, as described above, implies the same notion of truth as that found throughout the classical phenomenological tradition. It assumes the self-showing of the thing and the essential intentionality of experience. It accepts a notion of intelligibility in terms of insertion of that which one is seeking to understand into a larger structure, which then becomes its "explanation."

As to a criterion of "adequacy" there are some important assumptions as well. The adequacy of a structure as explanation for that which is integrated into it is determined by the question. If the integrating-explaining structure answers the question in the sense of providing an orientation for action within the relevant, presented context, then the spirit will be satisfied. As to the problem of the adequacy of the question, we have seen that that is determinable only in terms of the widest investigation of the field of possible experience, illumined by one's "natural faith."

This natural faith is fides quaerens intellectum-faith seeking understanding-if man does not block himself from fulfilling his nature. ${ }^{5}$ Phenomenology in the service of authenticity is phenomenology in the service of man seeking to be fully himself. He can be himself fully, in an era of historical awareness, only by throwing open the horizons of his understanding as far as historical science will allow.

It is here that the implications for a philosophy of education become apparent. In the design of an education the largest context-what we know of "man's place in the cosmos," as Max Scheler put italone provides the adequate ruling framework. Within this the development of consciousness in parallel traditions, Eastern and Western, a development that is by no means either simply progression or decline from a golden age but a complex movement of revelation and dissimulation, of distinct spheres of concern and common epochal horizons, has got to be explored. Central to any education must be the question of man's relationship to his fellows, to nature and to the divine dimension, from which, the traditions claim, come initiatives which pull man along his road of development, and from the demands of which he again and again falls away. Appropriation, which has to be learned in education, confronts the traditions' truth claims about the nature of these divine-human and human-human interactions, and should do so, as we said, in a way which increases consistently our awareness of the limits of our own starting faith.

It is part of the natural faith underlying the project of phenomenology to be confident that the Being revealing and dissimulating itself 
in and through historical becoming will prove sustaining of the human project, including the project of rationality, in the sense of which is all education. Appropriation in the service of authenticity, and authenticity as the quest for the sense of existence, give phenomenology its direction and meaning and education its mission.

\section{Notes}

1. Even earlier in fact than the Krisis der europaischen Wissenschaften, a work Husserl was engaged in until the end of his life, he had commented, indeed in 1924, "History is the great fact of absolute Being; and the ultimate questions, the final metaphysical and teleological questions, are one with the question about the absolute sense of history." I am grateful to Professor Robert Burch for calling this to my attention.

2. See my article, "Hope, Creativity, Appropriation: Natural and Supernatural Faith, Hope and Charity and Their Effect on Marxist-Christian Dialogue," in Dialectics and Humanism (Warsaw, Polish Academy of Sciences, Spring, 1979).

3. This contention is explored in my article, "Searching in History for the Sense of it All," in Review of Metaphysics, Vol. XXXII, No. 1 (Sept., 1978), pp. 37-52.

4. The relation between appropriation and authenticity is explored in great detail in a forthcoming work, Tradition and Authenticity, first volume of a multi-volume series in which appropriation is first explored as an instrument in the quest for truth and authenticity, and then illustrated by application, first to a tradition in which the author himself stands, Appropriating the Catholic Tradition, and then applied to the task of coming to grips with a foreign tradition, Appropriating Islam. The importance of and place in the world situation of these and the other major explicit traditions is analyzed in the second volume in the series, The World System. This entire undertaking is outlined in "A Strategy for the Pursuit of Truth," in Review of Metaphysics, Vol. XXXVI, No. 2 (Dec., 1982), pp. 287-301.

5. That he easily "derails" from the fullness of truth is shown and explained by Eric Voegelen throughout his remarkable work, The New Science of Politics (Chicago, University of Chicago Press, 1954). 